\title{
Classrooms with a Difference: Facilitating Learning on the Information Highway
}

\author{
Elizabeth J. Burge and Judith M. Roberts ( $2^{\text {nd }}$ ed.). Cheneliere/McGraw-Hill, \\ 1998, 142 pp., (plus resource kit - 86 pp.) ISBN 2-89461-160-9
}

This is a beginner's book. It is an easy read that gives 'newbie' technologists a first impression of what they should be thinking about when they encounter the impositions of information technology. The main advice to instructors, I think, is timeless - that technological implementation has potential benefits and pitfalls. In some ways, Information Highway is an introduction to the art of compromise in which some things are gained and other things are lost. The authors are well qualified to write a book about information technology in education. Both writers are frequently invited speakers on the college and university circuit. Elizabeth Burge has many years of experience in adult learning, including twenty years using various forms of distance technologies. Judith Roberts has been a project manager, seminar facilitator, invited speaker and writer.

As part of an ongoing series of books, the second edition of Facilitating Learning on the Information Highway is intended for the experienced teacher who wants plain talk about what one needs to know to implement technology in classroom teaching. The book is presented in a conversational style, as if drawn from discussions with Workshop participants. I suspect that many insights in these chapters were gained in this way. The workbook size of Information Highway gives the initial impression that there would be lots of exercises from which the reader could be taught how to facilitate learning on the information highway. This is not the case however. The book is not a self-instruction manual in that sense. Rather, it is aimed at experienced instructors, and as such, is a compendium of information about what can be done with technology. The premise is that experienced adults prefer to be told, not taught, the information. They want to be given alternatives to decide for themselves, what to do. Information Highway does just that. The advice is somewhat weakened however, with personal quotations that would have benefited from empirical support or at least, further elaboration. For example, consider this direct quote: "Let the techies figure out how to do it - I just have to figure out what to do and why” (p. 7). Some of us would argue that the 'what to do and why' of technology depends at least partly on 'what can be done' with technology, which in turn requires at least in part, 'knowing how best to do what can be done' with technology.

Information Highway is organized into two parts. Part One outlines some recent changes in how we think about education and training. Burge and Roberts select four technologies that define their values about the roles of technology and the nature of professional behaviour namely: audio, audiographic, compressed video and networked classrooms. The explanation for including these particular technologies appears later in the book (Chapter Six, p. 58). 
In Chapter Two, the authors present some basic organizing ideas about five key learner characteristics motivating drives to action, stages in development of thinking and group interaction, gender and cultural impacts on learning, and individual differences in learning style. The authors also introduce three types of ergonomic needs that learners bring to learning situations. It does appear, however, that the chapter could have used some more integration among the five learner characteristics.

Chapter Four is a pivotal chapter that covers a lot of territory, including selecting a model of teaching, specifying levels and objectives of learning, and addressing ten key planning questions. The sheer volume of critical topics and strategies discussed in this chapter may appear at once overwhelming and insufficiently covered to the reader. It would have been more useful, for example, to read how each of Pratt's five models of how people understand teaching, might be implemented and eventually, how each model might then appear, after successful adoption. Also in Chapter Four, Burge and Roberts present the technological novice with an overview of Patricia Cross's four models that describe teaching along a teacher-centred versus learner-centred continuum. However, one is left wondering how they are supposed to fit together with the different models already discussed. How does the newbie decide what to do first? It would have been helpful to see how each of the four models adopted from Patricia Cross could be implemented.

Part Two gives an explanation of the basics of audio and audiographic technologies, wherein the reader is encouraged to identify key opportunities, strengths, and limitations. The authors also explore Networked Learning and the basics of Compressed Video Learning technology. Finally, Chapter Ten provides a reality check with its three objectives: to present a framework for integrating elements in the learning environment; to offer a "Top Ten from the experience of writing this book"; and to expect the likely effects of "Murphy's Law".

The biggest strength of the book is its layout. The features and appropriate usage of information highway technology are concisely presented in a helpful decision-table format. There are plenty of graphics and tables in the book that help clarify the points made in the text. I liked the screen captures and equipment layout diagrams, particularly the presentation of the second imitation strategy for including adults in the learning process (p. 52). I think the "key issues" could be used as a checklist for workshop participants.

The biggest drawback of the book has to be the insufficient exploration of the technologies that are discussed. In my view, the value of the book as an educational resource would be improved with a deeper examination of the subtopics offered, in a way that entices the reader to investigate each more deeply. A more integrative approach to the models is also needed while keeping all the layman's language. There could be more elaboration and explanation of context and the sometimes conflicting learning outcomes to be expected in implementing these technologies in the classroom. Adults can deal with conflicting information especially when it is presented in a clear and balanced way. The conversational text should be accompanied by a bibliography that reflects more empirical 
research, and more contemporary and elaborated views of cognition and social cognition.

Taken in this light, I recommend the second edition of Facilitating Learning on the Information Highway for its intended audience, namely, professional educators who are new to technology and want to read about current technologies in ways that facilitate learning and communication.

Bruce L. Mann

Memorial University of Newfoundland 